\title{
KEEPING YOUR SANITY WHILE KEEPING YOUR STUDENTS: HOW TEACHER ENGAGEMENT CAN INCREASE STUDENT PERSISTENCE WHEN TEACHING STUDENTS DURING THEIR FIRST COLLEGE COURSE
}

\author{
Lynn Basko, Grand Canyon University \\ Crystal McCabe, Grand Canyon University
}

\begin{abstract}
Student persistence is a common concern for online educators. Previous research has shown that student persistence rates are effected by instructor presence, creating a sense of community in the classroom, and varying classroom activities for students (Croxton, 014). Based on the authors' experiences, there are three strategies for increasing student persistence among students taking their first college course. Using Web 2.0 tools (Zoom, Loom, Remind, and Flipgrid), increasing discussion board posts containing personal experiences, and using effective time management tools can allow instructors to increase student persistence rates. This article provides a brief literature review regarding student persistence and an explanation of the authors' experiences for increasing student persistence, as well as suggestions for further research in the area of student persistence and instructor strategies.

Specific skills needed for someone to become a spiritual leader were provided. These skills include self-awareness, self-esteem, effective communication, decision-making acumen, and the ability to promote and engage in healthy conflict. Each of these skills was examined and explained.

INTRODUCTION

A common concern in online instruction is student persistence, or a student's continued enrollment in a program at the end of each course. Student persistence is often influenced by a variety of factors, including student engagement, studentinstructor interaction, and delivery methods of content (Croxton, 2014). Research has shown that faculty members can increase student persistence by using strategies such as being accessible to their students, incorporating a variety of activities into their classrooms, and providing personalized feedback on assignments (Gazza \& Hunker, 2014). The following article provides a review of previous literature discussing the best strategies for retaining students in programs followed by the authors'

experiences of incorporating these strategies into their classrooms while teaching students in their first course of college.

\section{LITERATURE REVIEW}

Student persistence, or continuation, in a college program is a priority for online instructors. Student persistence in online programs is lower than student persistence in traditional, face-toface programs (Croxton, 2014). While there are many factors that contribute to whether or not a student chooses to continue in a program, there are many ways that the online instructor can influence student persistence rates. According to Croxton (2014) there are three ways that an instructor can influence student persistence: creating an active and social environment, providing a balance in
\end{abstract}


activities, and forming a sense of community in the classroom.

One way that instructors can increase student persistence is by creating a classroom environment that is active and social. The Community of Inquiry framework is another useful approach to studying online learning (Garrison, 2007). Community of Inquiry looks at three different areas: social presence, cognitive presence, and teaching presence (Garrison \& Archer, 2003). Active and social online environments might include discussion forums, cooperative learning opportunities, debates, and problem based learning activities (Croxton, 2014; Glazer \& Murphy, 2015). According to Croxton (2014) giving students opportunities to participate in a variety of ways is essential for increasing students' motivation to continue in their programs.

It is imperative that instructors create a sense of welcoming for students by getting to know students' personal needs and abilities (Croxton, 2014; Gazza \& Hunter, 2014; Glazer \& Murphy, 2015). Students also feel this sense of community through personalized feedback from the instructor (Rodriguez-Keyes, 2013). This concept mirrors that of social and teaching presence from the Community of Inquiry framework (Garrison, 2007). Studies show that there is a direct correlation between when students feel recognized as individuals and their performance in the course. Personalized instructor interaction led to higher levels of motivation and interest in the field of study (Glazer \& Murphy, 2015; Rodriguez-Keyes, Schneider, \& Keenan, 2013), which in turn leads to higher retention rates.

Student persistence can also be increased through the use of varied technologies within the online classrooms. Varied technologies give students more opportunities for interaction and a better sense of community and instructor presence (Dimeo, 2017; Foronda \& Lippincott, 2014; Glazer \& Murphy, 2015). These technologies can also be used for providing specific, individualized feedback, another factor that is directly related to student persistence (Rodriguez-Keyes et al., 2013, Ma, Han, Yang \& Cheng, 2015). When students and instructors are tasked with the use of Web 2.0 tools within the online classroom, cognitive presence is depicted. Cognitive presence is defined as the "exploration, construction, resolution and confirmation of understanding through collaboration and reflection in a community of inquiry" (Garrison, 2007). The following section details the authors' strategies for maintaining persistence among students following their first college course.

\section{AUTHORS' EXPERIENCES}

The authors found that there are many strategies for raising student persistence rates among students following their first college course. Strategies for maintaining high student persistence rates can be broken down into three categories: using Web 2.0 tools, sharing personal experiences in discussion boards, and having effective time management tools. These strategies align with research regarding student retention (Dimeo, 2017; Jones, 2013; Sandercock, 2014) and the authors' experiences support this.

\section{Utilizing Web 2.0 Tools}

Utilizing Web 2.0 tools is an effective way to increase student persistence as they allow for increased instructor presence and personalized feedback. Tools such as Zoom, a video conferencing website, allow instructors to meet with students synchronously, thereby increasing instructor presence (Basko \& Hartman, 2017). Other tools such as Loom and Flipgrid allow instructors to create videos for providing personalized feedback, personal discussion board posts, and explaining assignment details. Remind.com allows instructors to communicate with students via text message, and therefore give students information more efficiently. The authors' have found that integrating these tools into their classrooms has led to higher levels of student persistence.

Zoom is a video conferencing website that allows people to meet synchronously online from any location. Online instructors can utilize Zoom for initial course meetings to introduce themselves to students, meeting with students one on one to discuss assignments, or even meeting with small groups of students to facilitate cooperative learning. Research has shown that using video conferencing technology allows students to be active in their education and build relationships with the instructor and each other (Ellingson \& Notbohm, 2012; Tunks, 2012). Student persistence can be increased through the use of this video conferencing tool. 
Loom is a free Chrome extension that can be installed on your computer. It allows for a more personal style of feedback for students, without increasing your time spent. Through this tool, the instructor can capture their computer screen, along with their face (or opt to just have your voice), and record your feedback as you go through the student's paper. This allows the student to hear and see the feedback, with the option of watching it as many times as they need to until they have it right. An added bonus when using Loom is that the instructor receives a notification email when the student has viewed the feedback link. This helps instructors to feel more confident that their feedback is actually reaching the audience.

In addition to providing individualized, visual and auditory feedback, Loom can also be used to create videos that an instructor can upload in their classroom to show how to do something or where to find something within the classroom. One successful example of this is a Classroom Expectation video that was recorded using Loom and then easily sent out to each student at the start of the course. Loom can also be paired with other Web 2.0 tools, such as Remind, so that the video link is sent through a text to the student.

Flipgrid is a free Web 2.0 resource that allows for social learning to take place. Through this tool, instructors can create a grid, then add topics to create discussion amongst your students. The discussions take place through short videos. The instructor is able to moderate videos and provide feedback as well as set privacy rules. In a world where students are more comfortable, not only with technology but also specifically with technology that is accessible and quick in delivery, students tend to gravitate towards these type of discussion options. A couple of successful examples of Flipgrid being implemented in the online classroom have been, a community grid where multiple instructors are using the same grid in their classrooms, allowing for students from both undergraduate and graduate programs to feel more connected to their university. Another example is having students earn participation points for uploading videos on the class grid. A final, more specific to a course example is having students turn a video assignment from the class in to a topic on the grid. With this final example, all of the technology issues that sometimes accompany a video assignment are now eliminated, since everyone is using the same source.

Remind.com is a service that allows for text message communication between and instructor and a class without releasing private information to participants. Utilizing Remind allows instructors to communicate with either the entire class or one-onone with a student in real time. Students can post questions on Remind via email, text messaging, or the Remind app and instructors can reply from their chosen modality as well. Responses can be instant or scheduled for a later date. The authors have found that using Remind increasing student participation and presence. Additionally, as text messaging is currently the preferred form of communication among college students (Bobbitt, Inman, \& Bertrand, 2013), Remind is a great way to contact struggling students who may otherwise be unreachable through other modalities. Remind also allows for attachments to be sent, so students can receive resources such as instructor videos, announcements, and screenshots through the service as well.

\section{Sharing Personal Experiences}

In an online college classroom the teacher is a computer screen. Without engagement from the professor, students in the online modality will never know who their professor is nor anything about them. Some professors may believe that all a student needs to know is the curriculum that is presented in the course, but research shows that this is far from the case. According to Dimeo (2017), it is important for students to understand that their instructors are real people. John C. Maxwell (n.d.) said it best when he stated, "Student don't care how much you know until they know how much you care." One way to increase this engagement is through personalized discussion board posts. These posts can include descriptions of the instructor's own experience in the field, connections to how the instruction relates to the field of study (Sandercock, 2014), and humorous content to help the instructor and students make a personal connection (McCabe, Sprute, Underdown, 2017). These personal posts increase engagement and learning, which then leads to student persistence.

Sharing personally with students can sometimes make instructors feel uncomfortable, possibly even vulnerable; however, it is within these interactions 
that relationships can be built. As instructors, we are professionals in our field of content. This makes it easy to share our own personal experiences on the very topics that we are teaching about in our classes. The old saying, "learn from my mistakes" can also become teaching moments for our students. Whether we are sharing about a time that we made a mistake in our field or sharing about one of our successes, students are able to learn from those experiences.

\section{Utilizing Effective Time Management}

Having effective time management tools is another strategy that leads to higher student persistence, based on the authors' experiences. Student persistence is effected by timely instructor feedback and instructor interaction (Gazza \& Hunker, 2014; Jones, 2013) and having good time management allows instructors the time to meet these needs. Strategies such as using a weekly checklist for tasks and early grading have allowed for effective time management, in the authors' experience. Tools such as TypeItIn also increase instructor efficiency in grading assignments and providing feedback. Using these tools also allows for instructors to be more accessible to students as they have more time for phone calls, emails, and discussion board interactions.

One way to manage time effectively is to utilize a weekly checklist to keep track of required tasks and due dates. According to a study completed in 2013, online instructors spend nearly $52 \%$ of their time grading assignments and facilitating discussions in the discussion forums (Mandernach, Hudson \& Wise, 2013). Students rely on teacher feedback and discussion board posts to feel instructor presence, so these tasks are important, but it can be challenging for instructors to accomplish these tasks while meeting deadlines and completing other required tasks. Using a checklist allows instructors to stay focused on tasks and ensure that all grading and discussion board posts are completed in a timely manner, thereby increasing their presence in the classroom.

TypeItIn is a program that allows the user to save commonly used phrases, similar to saving items on a clipboard, to be accessed quickly for future use through the click of a button. For example, instructors can save common grading comments to the program and then be able to quickly add them to documents in the future. So, if an instructor needs to grade assignments from multiple students, they can quickly access comments that they use often without having to type them again each time. As online instructors are often teaching many students as once, having commonly used comments accessed at the click of a button can save a significant amount of time. The authors' experiences of using TypeItin rather than typing comments individually showed a notable difference in the amount of time spent grading assignments. This also allowed the authors to spend more time on individualized needs as the clerical portions of grading were completed in less time.

Online instructors can use many strategies in regard to student persistence and student retention. Using Web 2.0 tools, sharing personal experiences in discussion boards, and having effective time management tools are three examples of these types of strategies. The authors have found, based on personal experiences, that these strategies have given them a strong presence in the classroom and therefore increased student persistence and retention in their courses.

\section{SUGGESTIONS FOR FURTHER RESEARCH}

In their experience, the authors have found that using Web 2.0 tools, sharing personalized experiences in the discussion boards, and using effective time management strategies can lead to student persistence. Further research should be conducted to further support the use of these and other strategies (Croxton, 2014). It is also recommended that the use of additional Web 2.0 tools be explored in regard to student retention rates. Research in these areas will help increase rates of student persistence in online classrooms. 


\section{REFERENCES}

Basko, L. \& Hartman, J. (2017) Increasing student engagement through paired technologies. Journal of Instructional Research, 6, 24-28

Bobbitt, R., Inman, R., \& Bertrand, E. (2013). Using Remind 101 as a classroom communication tool. NACTA Journal, 57(4), 77-78. Retrieved from https://lopes-idm-oclc-org.library.gcu. edu:2443/login?url=http://search.proquest.com.lopes.idm. oclc.org.library.gcu.edu:2048/docview/1466250695?account id $=7374$

Croxton, R. (2014). The role of interactivity in student satisfaction and persistence in online learning. MERLOT Journal of Online Learning and Teaching, 10(2), 314-325

Dimeo, J. (2017). Improving instructor-student engagement online. Inside Higher Ed, Retrieved from https://www.insidehighered. com/digital-learning/article/2017/09/27/instructors-suggestdigital-tools-improving-engagement-online

Garrison, D.R. (2007). Online community of inquiry review: Social, cognitive, and teaching presence issues. Journal of Asynchronous Learning Networks, 11(1), 61-72

Garrison, D.R., \& Archer, W. (2003). A community of inquiry framework for online learning. In M. Moore (Ed.), Handbook of distance education. New York: Erlbaum.

Ellingson, D. A., \& Notbohm, M. (2012). Synchronous distance education: Using web-conferencing in an MBA accounting class. American Journal of Business Education, 5(5), 555562. Retrieved from http://search.proquest.com.library.gcu. edu:2048/docview/1418446127?pq-origsite=gscholar

Foronda, C., \& Lippincott, C. (2014). Graduate nursing students' experience with synchronous, interactive videoconferencing within online courses. Quarterly Review of Distance Education, 15(2), 1-8. Retrieved from _https://lopes-idm-oclcorg.library.gcu.edu:2443/login?url=_http://search.proquest. com.library.gcu.edu:2048/docview/1625397159?account id $=7374$

Gazza, E., \& Hunker, D. (2014). Facilitating student retention in online graduate nursing education programs: A review of the literature. Nurse Education Today, 34, 1125-1129

Glazer, H., \& Murphy, J. (2015). Optimizing success: A model for persistence in online education. American Journal of Distance Education, 29 (2), 135-144

Jones, R. (2013). Keeping students engaged in the online classroom. Faculty Focus, Retrieved from https://www. facultyfocus.com/articles/online-education/keeping-studentsengaged-in-the-online-classroom/
Ma, J., Han, X., Yang, J., \& Cheng, J. (2015). Examining the necessary condition for engagement in an online learning environment based on learning analytics approach: The role of the instructor. Internet and Higher Education, 24, 26-34

Mandernach, B.J., Hudson, S., \& Wise, S. (2013). Where has the time gone? Faculty activities and time commitments in the online classroom. Journals of Educators Online, 10(2), 1-15

McCabe, C.L, Sprute, K.M., \& Underdown. K.O. (2017). Laughter to learning: How humor can build relationships and increase learning in the online classroom. Journal of Instructional Research, 6, 4-7

Rodriguez-Keyes, E., Schneider, D., \& Keenan, E. (2013). Being known in undergraduate social work education: The role of instructors in fostering student engagement and motivation. Social Work Education>The International Journal, 32, 785799

Sandercock, I. (2014). How important is instructor presence in an online course? Arizona State University TeachOnline, Retrieved from https://teachonline.asu.edu/2014/10/ important-instructor-presence-online-course/

Tunks, K. W. (2012). An introduction and guide to enhancing online instruction with web 2.0 tools. Journal of Educators Online, 9(2), 1-16. Retrieved from https://lopes-idm-oclc-org.library. gcu.edu:2443/login?url=http://search.ebscohost.com.library. gcu.edu:2048/login.aspx?direct=true\&db=ehh\&AN=7830480 $4 \&$ site $=$ ehost-live\&scope=site 


\section{THEORETICAL, REVIEW \& REFLECTION ARTICLES}

